\title{
A Lightweight Co-Construction Activity for Teaching 21st Century Skills at Primary Schools
}

\author{
Samuli Laato * \\ University of Turku \\ sadala@utu.fi
}

\author{
Nicholas Pope * \\ University of Turku \\ nicholas.pope@utu.fi
}

S. Laato and N Pope contributed equally to this work.

\begin{abstract}
Employing learning processes that promote 21st Century skills is now a requirement in Finnish schools and elsewhere. Participatory design/co-design activities have shown to foster design thinking and computational thinking skills in primary school level participants, but a lightweight applicable model of such an activity is yet to be presented. We develop a lightweight hybrid co-construction method based on software development via two exploratory case studies in a Finnish primary school. For the purpose of evaluating objectively the motivating effects of our activity, we elaborate upon four concerning dimensions that arise from previous studies. In our resulting activity, an adult programmer is partnered with a group of children to, in this case, construct math games together. The children felt empowered and motivated by working with us in this way, however, further study is required on the effects this kind of an activity has in comparison to alternative teaching methods.
\end{abstract}

\section{Introduction}

In 2016, Finland implemented a new school curriculum that aims to develop 21 st century skills by using technology and novel learning processes across disciplines $[8,59,60]$. Schools need to develop practical ways to meet these new demands over coming years. One starting point is with children making or designing educational games which is now generally accepted as a valid learning activity for 21 st century skills $[30,32]$ and has been explored in three different but overlapping fields of research: codesign with children [16,38,39], constructionist game making $[11,17,31,34,56]$ and serious games [30]. Each field has independently developed a number of methodologies $[13,33,55]$, performed a multitude of case studies and reached conclusions about a range of subjects from group dynamics [52] and adult involvement [58] to learning outcomes [30,44,58] and methods of evaluation [14,53]. Common to each of these three fields is an underlying need to efficiently motivate and engage the children in the activity for best effect. Despite this, a number of persistent issues arise in the individual fields that potentially hinder motivation, and which could be addressed effectively in a selectively hybrid co-construction approach. One issue is the impractical and heavyweight demand on teacher resources for some activities. our further interwoven aspects to keep in mind when constructing a motivating co-design activity are:

1. The significance of immediate objective feedback.

2. Limitations of lo-fi interaction design.

3. A tension between tool complexity and flexibility.

4. The role of adult facilitators.

With this exploratory study we aim to bring Participatory Design (PD) activities a step closer towards a sustainable part of standard elementary school education in Finland. In this research we bridge together professional software development and primary school education, as we empower children to design and create educational math games together with the help and guidance of an adult programmer. In order to evaluate the educational potential and motivational effects our activity has on the participants, we focus on the four interwoven issues listed above. We explore the effects on student motivation through two alternative lightweight co-design studies. Based on our initial study and the lessons learned, we evolve our activity in the second study towards the final hybrid methodology, which will be the primary topic and the main contribution of this paper. The research question we seek to ultimately answer in this study is: Are co-construction activities focusing on software development a viable and sufficiently lightweight option for teaching 21st century skills at primary schools?

\section{Background}

Participatory Design and co-design [50], in this paper specifically refer to an intergenerational but balanced collaboration between adult experts in design and children who are the domain experts for software targeted at children $[10,19]$. The focus of PD is primarily on the design phase(s) of a larger project in order to empower participants in shaping technology or to encourage design thinking, 
although it can follow through to the testing and evaluation of products or prototypes. However, professional developers are involved for the implementation phase and the children are not usually involved in any programming activity. In contrast, constructionism is a learning approach revolving around the significance of the act of making in knowledge formation [20:1,40] and so it often focuses heavily on teaching programming skills and computational thinking to enable digital construction [30,56,57]. Both PD and constructionist making activities have explored the creation of educational games by children under various names such as Participatory Game Design [16,38] and Game-Based Learning $[29,31,44]$. The following sections explore the four identified aspects across the three fields of study with respect to efficient child motivation.

\subsection{Significance of Feedback}

Experiential Learning Theory (ELT) [35] and Empirical Modelling (EM) [5,6] both elaborate upon and give a philosophical account of the vital nature of creating personal experiences to be observed, explored and experimented with in order to learn. Constructionism deliberately takes advantage of direct and immediate objective feedback from the constructed artefacts which have been referred to as "objects-to-think-with" by Papert [40]. These provide continual experiences [31] rather than structured and iterative experiences mediated by adults. EM goes one step further by emphasising the role of continual (non-iterative) interaction and observation of an informal kind by calling similar constructed artefacts construals [6], or "objects-to-converse-with". The reference to conversation is also a reference to the use of such digital artefacts as a way to communicate and collaborate by providing a common rich objective referent upon which feedback and discussion can be focused.

Studies into the power of feedback when learning also indicate that self-regulated feedback is the most effective kind [23], and that confidence in the resulting feedback is critical. It is perhaps the act of conversing with objective artefacts rather than with adults alone that can enable an internal autonomous motivational drive, and as Piaget states: "each time we prematurely teach a child something he would have discovered himself, the child is kept from inventing it and consequently from understanding it completely" [6,42]. Children can ask questions of or discern feedback from the artefact which corresponds to their current idiosyncratic thoughts in a way an adult could only guess at when trying to provide similar verbal feedback [7].

Serious games research has brought ELT in as a pedagogical theory about the importance of unbroken flow experience for maintaining engagement in games [33], and should also be considered when children make those games. A common characteristic of a PD activity, however, is that adults provide the expert feedback connection between generally low-fidelity prototypes worked on by the children and an as yet imaginary software product $[15,33]$. Research into Participatory Game Design with children has identified that multiple forms of feedback from experts about these designs is essential in helping the children to reflect upon those designs [16]. Nonetheless, acting as filters and intermediaries, the adults often inadvertently bias and undermine the design process based upon their values and assumptions [45,58], leading to a reduction in the sense of ownership over the activity by the children and a potential corresponding loss of motivation [15]. Further, the feedback is often far more iterative and disconnected in character, especially if developers need to create the prototypes away from the children, breaking the flow experience. Maximising autonomous self-regulated feedback [23] from objects-to-converse-with should be a target for a game making methodology, even if unachievable at the extreme.

\subsection{Limitations of Low-Fidelity}

Looking beyond the concerns of lo-fi prototypes requiring additional expert feedback, some PD studies involving games have indicated the problems which developers encountered when having to write software from low-fidelity prototypes produced by children [32,38]. The comment being that interaction and game play dynamics are not adequately expressed in lo-fi artefacts and that, therefore, the designs could not be utilised directly but required extensive reinterpretation by the developers. In our own previous attempts at codesigning a maths and music game with primary children [37], we also encountered the challenge of explaining complex design issues to children with paper in-order to move forward. Our conclusions can be found in the first case study below. This difficulty in eliciting useful game-design ideas from children when only low tech approaches are used is discussed further in [32]. If children's ideas cannot be captured and acted upon, it is not too difficult to imagine a sense of disillusionment on the part of the children when the results of their design efforts do not match what they had in mind.

\subsection{Maker Tools}

Tools utilised in making games at primary and secondary level range from simplified programming languages such as LOGO [40] and Scratch [49], to specialist tools [1,12] or full programming languages. There is also a considerable body of research on End-User-Programming environments to simplify programming, and some of these have been used with children to make games $[47,48]$. Past projects exploring game-based-learning have created their own bespoke game making environments and concluded that more options would be required to sustain interest $[12,41]$ - in other words - a more general tool is necessary. Which tool or tools to use 
depends upon age-group, educational resources for teaching programming and the nature of the activity, but one common dimension is that of complexity vs flexibility and balancing both to achieve maximal motivation in the children. An excess of complexity leads to frustration and a breakdown in flow experience, whilst limited flexibility inhibits the expression of imaginative ideas resulting in boredom [41].

There is little we can add to this ongoing and extensive debate, except that it is our view that using simplified tools is potentially an unhelpful shortcut for the children who may benefit from alternative motivational strategies for learning the real thing. A comment we have noted from children on a number of occasions is "finally, we are doing serious programming" [21], perhaps indicative of a frustration at toy environments including, in this case, Scratch. Baytak and Land in [3] found that one girl (the only girl in that study), who otherwise lacked motivation, did develop a willingness to learn basic programming skills in order to add actions and effects to her game. It is a self-motivated request to learn about programming that we aim to nurture and we suspect the tool matters less than motivation.

\subsection{Role of Adults}

From the need for feedback, the need for tool instruction and game design expertise, adults must be involved $[32,38]$. With the problems described in previous sections, there is one more to add: most schools cannot have 4-6 teachers or researchers per class to sustain an activity, and we, for example, only have two researchers available. This concern is particularly pressing now due to the need to apply such methods across the curriculum in Finnish schools. The ubiquity of constructionist activities may in part relate to the low requirements for adult facilitators. Unless there is a practicable means by which schools can apply a methodology for learning then there is little point in developing such a methodology. It is therefore not plausible to pursue a PD approach most of the time and the sustainability of PD activities is critiqued as being very dependant upon the researchers and adults involved [27,51]. Research into the dimensions of adult-child interactions with respect to PD activities [58] needs to be carefully considered to achieve a balanced partnership during the making activity, especially given a low number of adult participants where the burden on the adult must be reduced through involving the children more and where the actions of any single adult have a greater impact. The political empowerment motive must not be forgotten either

\subsection{Summary}

In both literature and experience, PD highlights the significance of feedback. PD activities can scale to larger and more significant projects, however, whilst constructionist activities have an answer for feedback they suffer from tool choice and complexity problems that may, at primary school level, be both off-putting for children and limiting factors. These two issues form the key dimensions to be balanced and determine a third, that of the role of adults in any activity. PD may not be practical, however it has a lot to say on equality, empowerment and motivation [28], something constructionist making practices can benefit from. Working with adults as equals can promote a sense of power, influence and confidence.

\section{Two case studies}

This section presents two game making case studies, which will be referred to as Study 1 which took place in Spring 2017, and Study 2, which took place in Autumn 2017 at a primary school. Our overall goal for the studies was to develop the PD process in a lightweight direction so that it can be used as a part of primary school education. The problem with existing studies is the number of adult facilitators and resources required to maintain the activity. Whilst removing adult resources from the process we wanted to sacrifice as little as possible from the positive learning outcomes and motivational elements of previous PD studies, and additionally explore if our new activities were effective as a way of creating usable software.

For our first attempt at a lightweight activity, in Study 1, we created a structured activity taking inspiration from Cooperative Inquiry $(\mathrm{CI})[10,19]$, and attempted to scale it up for a greater number of students with only one adult facilitator present. In the resulting activity we engaged the students with pre-engineered design exercises to elaborate upon an existing game, which had previously been co-designed at the same case school [36]. After the evaluation of Study 1 and the lessons learned, we moved towards a more student driven and constructionist approach, drawing influence from agile software development, to address the challenges we faced relating to the four aspects identified in the in the first section of this paper. We also added an extra adult resource for Study 2, but compensated by designing the activity so that no preparation work was needed before the sessions. The second study is our exploration of a hybrid co-construction activity.

\subsection{Participants}

Both case studies were carried out at Pääskyvuori Primary School, Turku, Finland in 2017 as a voluntary school club. The students guardians were asked to sign consent forms which explained the research agenda and all participating children had the option to leave the voluntary activity at any time, as a few did. The whole activity was conducted under the supervision of the school's principal. In the first study, 21 4th and 5th grade children (ages 11 and 12) participated in almost all weekly sessions (6 girls), and in the second study 16 students participated (6 girls), of whom most were the 
same students as in study 1. Dropouts are not included in these numbers and the only adults directly involved with the activity and present at all times are the two authors of this paper.

\subsection{Study 1 Method}

The activity was held in the form of a weekly club on 8 occasions for two different groups of children. Within our research setting, our goal was to co-design further an application called Harmony Hippo, which focused on composing music with mathematics, and was developed and preliminarily tested at Pääskyvuori school in winter 2016-2017 [37]. Our overall goal of creating a sustainable lightweight activity meant, we were unable to adopt, for example, a Cooperative Inquiry type of approach which is usually held with 3-4 adults per 6-8 students [19]. As no other approach presented in the background section of this paper was suitable for our needs, we decided to shape our own activity drawing inspiration from Cooperative Inquiry [10], Hevner Design Science [26], our previous work at Pääskyvuori school [37] and gamified co-design in primary schools [9].

Study 1 activity was organised the following way: the students were split into two groups of 10 and 11 students respectively. Both groups had a 1 hour long design activity session per week, where they engaged in designing and developing our target artefact via pre-engineered tasks and exercises. Both groups were given the same artefact to work on. Our process was iterative, so that each week's exercises were based on the students decisions the previous week, and we kept working on the areas of the application the students chose. In contrast to Study 2, Study 1 comprised of several activities which were attempted in order to allow students to work on the game design. Activities attempted during Study included:

- Design user interfaces (UI) by drawing with pen and paper.

- Designing UI using the GNU Image Manipulation Tool (GIMP).

- Writing feature suggestions on pieces of paper.

- Group work and collaborative discussion on which features to implement and in what order.

- Teaching students required concepts in math, music and software design.

- Storyboarding [55]

- Testing students knowledge on math, music and software design.

The role of the adult in the process was to plan the sessions based on the students work, and guide the activity in a fruitful way. This approach meant the children were told what to work on, and were able to influence the design sessions only by voting and suggesting ideas. Such a limitation forced all students to work on the same component, depriving the group of the possibility of playing to each individual's strengths. In our case one adult facilitator was present during all sessions (author 1). Data was collected through interviewing the students during and after the co-design sessions, as well as by collecting all the drawings, graphics, design documents and tests that the children produced during the sessions.

\subsection{Study 1 Results}

During the entire course of our 8 session activity, 8 students dropped out. We asked the remaining 21 students to fill in a final questionnaire regarding the activity. The majority of the students $(15 / 21)$ who continued the club until the end, said they would like to carry on attending the club if it continued. Student feedback was mostly positive, however a few students voiced verbally that the club was boring. The students' level of engagement during the entire course of the activity dropped towards the end in general, with fewer drawings, design decisions and materials provided by the students over time. However, a few students maintained their enthusiasm until the end. Unsurprisingly the students who were the most motivated were also the ones whose design ideas and suggestions were taken into account the most in the artefact.

The improvements made to the Harmony Hippo composing program were minimal. The only concrete design decisions reached with the students involved them voting on a set of provided design options. Most activities involving creative exercises such as drawing UIs, or coming up with new ways for composing, were unsuccessful in producing material or ideas that could have been utilised in the application. In our case, the students seemed to lack the ability to imagine meaningful improvements to the already quite far developed program. Despite sufficient math knowledge, as per a math test we gave the children, the design tasks illustrated their inability to draw connections between math and music, and furthermore, based on the design test and all other tasks students engaged with over the course of the activity, students had difficulties in integrating mathematics into applied fields generally. Similar results can be seen in previous studies [31,32] and in Study 2.

\subsection{Evaluation of Study 1}

We evaluated the exploratory activity based on the 4 key areas mentioned in the background section of this paper as well as by looking at the improvements made to our target artifact. Firstly, immediate objective feedback for the children was not present in our activity. The implementation of the students ideas to our artifact software was done outside the activity, and as there was only one artifact, most children never got to experience feedback on what they did, other than occasional comments. Figure 1 demonstrates 4 UI designs from individual students, which without rapid and 


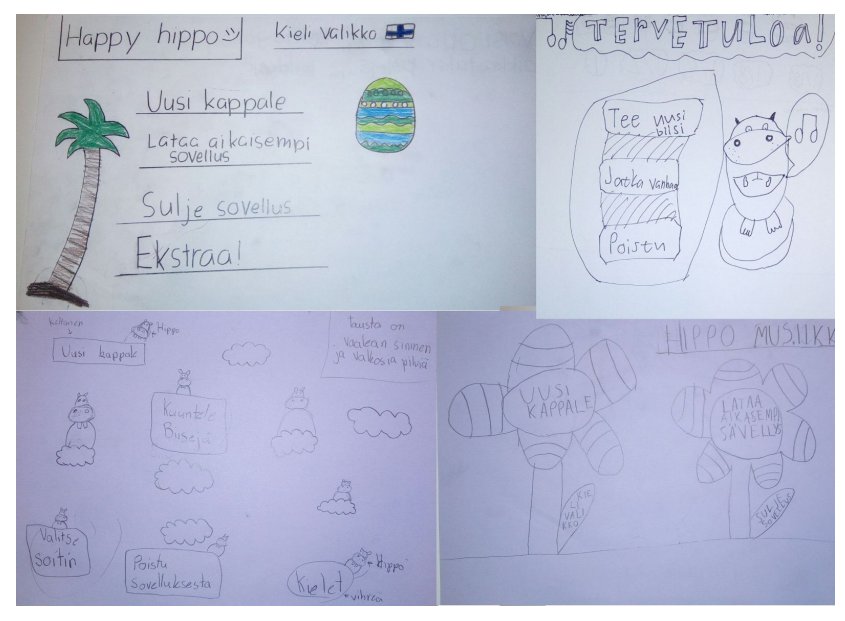

Figure 1. Showing UI designs from 4 individual students.

continual feedback, they were unable to design further, as students were unable to see how their design looked and acted in practise. Secondly, children expressed their interest in getting to write code themselves instead of being forced to use storyboards and other non-technical design tools to express their ideas. Thirdly, the single adult facilitator was overworked in his attempt to take into account all the ideas children generated during the activity. Finally, the overall improvements made to the target artifact Harmony Hippo were almost non-existent.

The Study 1 approach could not adequately harness the individual expertise of the children, as, for example, some were skilled and interested at drawing and designing UI, but only got to do that on two sessions during the entire process. This effectively forced students out of their comfort zone, which can be seen as a good thing from an educational point of view but might hinder students' motivation and hurt the development of the artifact. Additionally the students' lack of skill and knowledge of the technical tools limited the types of exercises that could have been successfully attempted. The use of lo-fi tools is suggested throughout literature, but the children preferred to learn to use professional tools. Both groups stated explicitly that they want the artifact application published.

In order to solve the issues of the Study 1 activity, we decided to reduce group sizes, as throughout literature group sizes of 4-6 students are suggested in similar activities $[9,19]$. Additionally, we decided to give each group an individual artifact to work on, in order to increase the amount of feedback students were able to obtain on their decisions. Based on theory, our hypothesis was these changes should lead to empowerment and increased ability to take design ideas further, and consequently have a positive impact on motivation [46]. In order to integrate immediate feedback into our activity, whilst maintaining or improving the lightweight nature of study 1 , we started to feel that a standard PD activity would be more effective if combined with a construction activity for the children. The children seemed keen on the idea of creating real software themselves, which several students verbally voiced throughout Study 1 activities. Thus, we refrained from moving towards paper or lo-fi prototypes in our design of Study 2 . However, simply reducing group sizes and giving each group an individual artifact to work on was an issue in our case, as our overall goal was to come up with a practical relatively low-cost activity. In Study 1, each session required 2-4 hours of preparation work from the adult facilitator. Eventually we came up with the activity presented in Study 2 that addresses all the mentioned issues.

\subsection{Study 2 Method}

To address the problems with our first lightweight study, and our subsequent identification of the four issues stated in the introduction, we looked to explore a co-construction method as a hybrid between intergenerational PD and constructionist making activities. Inspiration for this method comes also from agile software development practices such as extreme programming and specifically an expert-novice pair programming strategy [43]. Our reasoning is that increasing the scope of what children can create without them needing to be expert programmers already, will improve motivation and a sense of empowerment. Additionally, to incorporate the major strengths of constructionist activities, namely the live feedback from a constructed artefact, would potentially reduce demands upon adult participants whilst boosting learning effectiveness over lo-fi prototyping or adult feedback alone. In order to ensure that the Study 2 activity remained lightweight, and that the children could see all the stages of development, we decided to completely remove all work done by the adult facilitators on the artifact outside the activity sessions.

Our starting point is to use adult facilitators (the authors) as "programming monkeys" to be led through development entirely by the children. Initially the children would provide designs and content and a rapid prototype would be coded by the adults in a language or environment of their choosing. As a first step we would limit the applications to math games and ask the children to come up with a team name and logo. Beyond this the method is allowed to evolve during the study as we identify how to both maintain motivation and the effectiveness of the activity with respect to the usual learning outcomes $[30,44]$. One key element is that minimal if any work should be done by the researchers outside of the sessions so that a) the children see the entire process and b) to keep the process lightweight. A second element is to make it clear to the students that the games would be published and the success of the game depended entirely upon their efforts. Further changes with respect to study 1 involved:

1) reducing group sizes to a more optimal 5 students $[24,52]$, 2) starting from scratch rather than from an existing game for reduced initial complexity / greater ownership and 3) having a more relaxed environment for the children where they were 


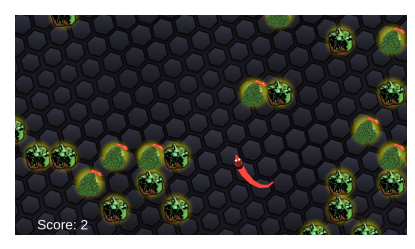

(a)

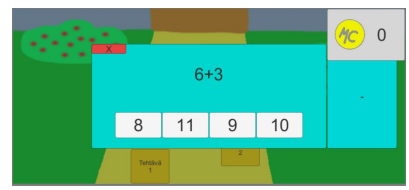

(c)

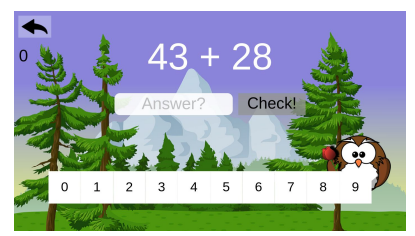

(b)

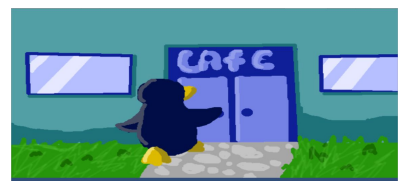

(d)
Figure 2: Games created during study 2. a) Math Snake, b) Gold Fist Games, c) VVSH Games), d) Pulla Pingviini

free to play and use their phones if desired [19].

For data collection, we decided to film the co-construction sessions, as well as write down notes on anything peculiar or interesting we observed during the study. External observers, including the school principal, were present on some occasions to offer evaluation. Additionally we saved all of the materials produced by the children, including drawings, design documents, computer drawn graphics and the applications they developed.

\subsection{Study 2 Results}

Each of our 4 groups created their own game during the Autumn 2017 sessions. Two groups used the Unity 3D platform for app development and the other two groups a JavaScript based online platform called Construit [61]. All graphics were either drawn by the students themselves using available drawing programs like GIMP, or found, selected and edited from the internet among freely available pictures. Some instruction was required to support their drawing and downloading of graphics in a form usable by the programmer. Since the programmers were present as team members, the students were rapidly, within a single session, able to grasp the scope of what was and was not possible. As the design work progressed, we also started to let the students attempt simple programming at their request. Screenshots of the 4 applications that were created can be seen in Figure 2. Games (a) and (b) were made under the same researcher (author 2) using the online platform and both can be found online $[62,63]$. Games (c) and (d) were created under the second researcher (author 1) using the Unity3D game creation platform. Groups (a) and (d) consisted of 6th grade elementary school students and groups (b) and (c) consisted of 5th grade students. Game (c) is perhaps the most student driven of all 4 games, as the students designed the game, drew the graphics themselves and even got significantly involved in the programming. On the other hand, game (a) was influenced by the adult the

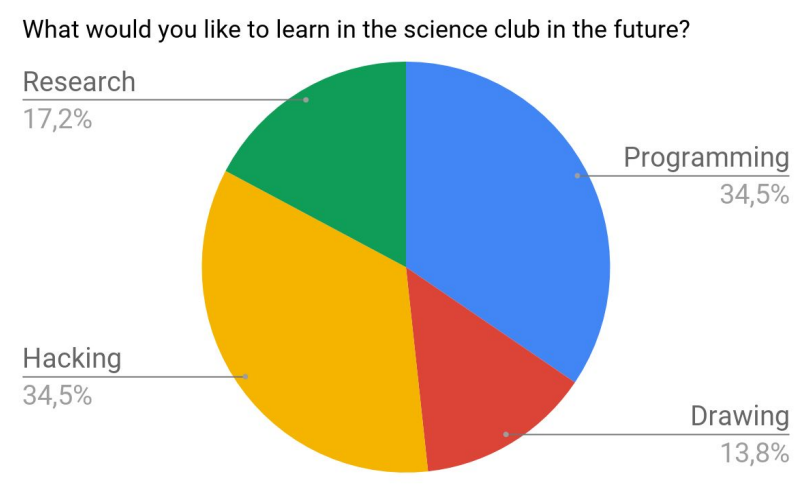

Figure 3. Students wishes for the science club in the future.

most since the game idea was quite demanding for the programmer, and less so for the graphics artists and designers.

In game (a), the user is tasked to control a worm and eat fruit. Each time the worm eats a fruit a math calculation is presented to the user. If the calculation is answered correctly, the worm grows. In game (b) the player is tasked to enter worlds to solve calculations. By solving calculations, the player can progress to the next world to solve more calculations. The player earns rewards by doing so, and can use the rewards to customize his/her character in the game. Game (c) is essentially the exact same idea as game (b). Finally, game (d) tells the story of a penguin who gets offered a job at a cafe. The penguin accepts and starts looking for the best recipes in the world. The idea of the game is to solve food related problems and calculations in order to obtain recipes, which can then be viewed from the main menu. During the final session of study 2, we asked the students to fill in a feedback survey containing 4 sets of questions that can be categorised into asking about i) the students contributions in the co-construction process, ii) how the students would improve the co-construction sessions, iii) what learning outcomes the students thought they had and iv) how motivated were they concerning the club, computational thinking and mathematics. All together 14 students replied to the survey. Out of 14 students, 12 wanted to continue the club next year, and 2 were unsure whether they wanted to or not. 6 of the 14 students were girls, and they all replied to have greatly enjoyed the club.Exactly half of the students 7/14 wished the club was held more often, and the other half were unsure whether they wanted to or not. Overall we can conclude that students enjoyed the science club and were almost uniformly interested in continuing designing applications together with the adult mentors. Figure 3. shows the students replies to what they wished to learn in the activity in the future. Most students wish to learn programming, including 5 out of the 6 girls that attended the club. Furthermore, 7 students replied to have learned 


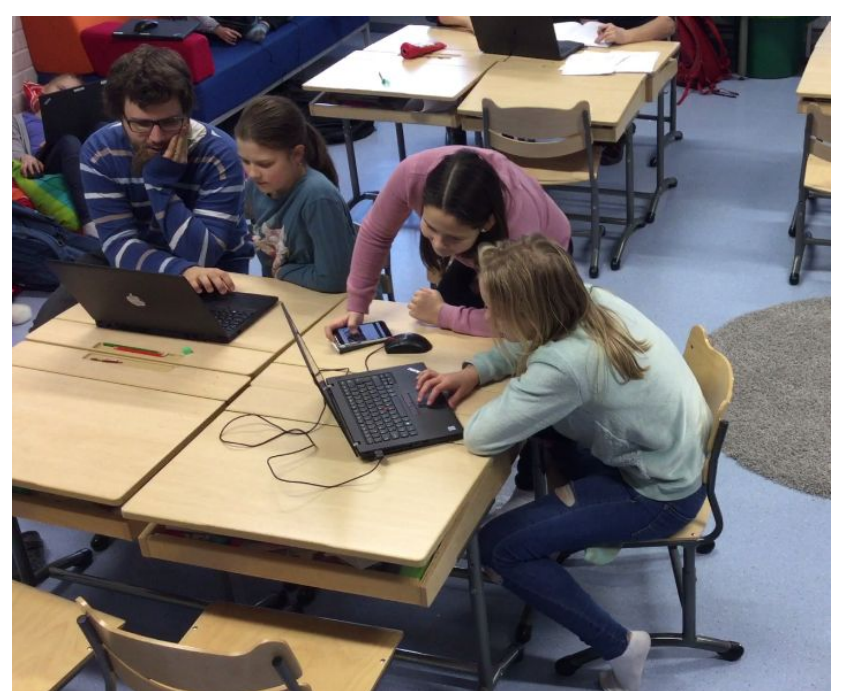

Figure 4. Group (c) working with the adult facilitator (left) on their application.

programming during the science club and 6 were unsure if they learned or not.

Finally, in category (i) we asked 9 questions about how the students felt about their own contributions in the construction process. This was done to figure out whether they enjoyed the Study 2 activity or not, and whether it was potentially useful for them . In our case, 13 students out of 14 felt they participated in the creation of their groups application and 10 out of 14 students felt they were helpful, or significantly contributed to their application. Therefore, the results of this case study indicate that a co-construction process, where the children themselves are responsible for choosing what they will work on, and where group dynamics play a big part, can foster a boosted sense of ownership and empowerment in all, or at least almost all the participants.

\subsection{Evaluation of Study 2}

The students involvement and engagement was higher in Study 2 than in Study 1. This could be seen in both the survey results and observations by the researcher(s). Contrary to Study 1, after Study 2 several students came voluntarily to ask if the club was being continued. Additionally, many students hoped for more sessions or longer sessions during and after Study 2. The changes made to the process between the two sessions are the most likely contributing factors, although the students were those who already knew what to expect, unlike in the first study. One of the largest improvements in motivation during the study was immediately after they had access to the prototype game on their own devices (laptop or phone), at which point their focus solidified onto the task. Similarly, whenever they created art with GIMP, or downloaded some, they could very rapidly see how it looked in the actual game, and whenever they wanted to change some text or move some button they could immediately see it happen.

Any motivational problems for the students during the co-construction sessions seemed to arise from a sense of powerlessness. When interviewed, the unmotivated students almost without fail replied that they had no idea how they could contribute to the design. In our case, half of the groups had an adult member who did not speak their native language which made the management of challenging group dynamics difficult and meant some children struggled to find a role. Despite this language challenge, these groups overall still managed to stay engaged, in part due to the relatively reduced significance of the adult and an increased reliance on objective feedback from the artefact, but also because they demonstrated a remarkable capacity to self organise their efforts in a coherent way.

Substantial differences in the students initial abilities to draw using the GIMP tool could be seen, as some had practised previously at home. The more initially skilled students were also more engaged overall, and initially less skilled students we demotivated by their struggles to learn new skills. A final point on this theme is to, in the future, better guide the design such that the balance between programming complexity and other tasks is such that the children always have enough to do. It was apparent from game (a) that too much burden was placed on the adult, leaving the children with too little to do in the last weeks. There was, however, a persistent desire from many of the children to learn programming. By the end of the study their apparent passion for learning programming was high, as the survey revealed, and so more effort could be directed to teaching this which would help provide more roles later in the project for the children.The workload per adult participant significantly decreased compared with Study 1, as there was no longer a need for extensive evaluation and preparation before each session. This consequently, together with the children's boosted engagement, led to an increase in motivation for the adult participants as well. Maintaining motivation for the adult and student members alike is of utmost importance for an effective design process to take place and so more consideration must be given in the future to the social role of the adult $[19,52,58]$.

On the quality of the resulting games: out of the 4 artifacts, the integration of mathematics into the actual gameplay was only achieved in one. The groups (a), (b) and (c) all had basic math calculations glued on top of the game. Solving them was a necessary task in order to progress in the game, but other than the result being right or wrong, the calculations had no effect on the gameworld. This result echoes with what we found in Study 1 and in literature $[31,32]$. However, group (d) came up with the idea of using mathematics to measure cooking ingredients to create recipes. This idea was a good example of integrating math into the gameplay and it was developed by a group where the majority of members were girls. The students still struggled 
to implement their idea in practise. Otherwise, the students seemed to be well equipped to design basic applications, requiring only a little help in the design decisions from the adult participants. However, generally they focused more on menus, backgrounds and simple elements than on gameplay which tended to be recycled from games they knew $[4,36]$. With groups of maximum 5 people and a programmer, we were able to avoid situations where some of the students ideas could not been showcased in the actual application, unlike in Study 1 and other previous studies [46].

\section{Discussion}

Out of the two exploratory case studies presented in this paper, Study 2 yielded more promising results in terms of our goal of constructing a lightweight co-design activity for primary schools. The positive attitudes students showed towards programming especially after Study 2, and their desire to learn more, are promising results from an educational standpoint, since programming integrates many skills that have been identified in studies to be essential in developing an interest in the STEM fields later on, such as mathematics and computational thinking [2,18,57]. Furthermore, it shows an encouraging match to the overall Finnish curriculums agenda with regards to integrating 21 st century skills, including programming. Evaluation by our host school stated that the children involved did learn 21st century skills as per our remit, and that we were successful in making coding relevant to the children.

With respect to why a hybrid co-construction strategy should be pursued in schools, it is useful to briefly take a look at directions others have taken to improve engagement in PD activities. We did not explore gamification of the activity itself, for example, as others have done [9], nor did we explore other lo-fi prototyping techniques as some CI methods have suggested. Neither of these directions radically alters the four issues we identified in the introduction and any improvements in child engagement must be weighed against extra time requirements for the adults in preparation. With a multitude of factors impacting the students level of engagement, motivation and learning, further study on our hybrid activity is needed for conclusive results on learning outcomes.

When comparing required adult resources of our activities to previously established practises of CI activities [19], assuming that we maintained similar learning outcomes, we managed to reach a roughly 3-fold improvement. Additionally required adult participation diminished over time. The major contributing factor for this is the self-motivating aspect of our activity. In our case most of our 11-12 year old participants, especially the girls, stayed motivated throughout Study 2 sessions to work on their artifact. Based on this study, children aged 11-12 are old enough to design and strongly participate in creating software, and more specifically, educational games.

\section{Limitations and future directions}

A few critical concerns still exist with our co-construction method when it comes to meeting the above goal in schools: 1) what is the availability of expert programmers more broadly if schools wish to pursue this activity at scale. 2) If all students must participate, and not just volunteer, then the activity must not leave anyone behind and must motivate the majority of students. 3) was it the effect of reducing group sizes or the introduction of hi-fi artefact construction which was responsible for the improved results? And 4) did starting from scratch rather than from an existing game also have an impact? Further, there were no controls or pre and post tests involved to quantify any of the benefits of this co-construction method.

In the future we will continue co-construction activities in further studies, as requested by the children and the school, and observe the long term learning and motivational effects it has on the participating children. It is also our intention that over a longer period the co-construction activity will involve systematic teaching of programming but at a suitable pace and always in an applied fashion. Study 2 activity must also be applied to other themes than math games, for example a biology theme. Pääskyvuori school, for example, intends to merge this co-construction activity into all aspects of the school curriculum over the next few years, including music, dance, history and science. Therefore it is essential to shape the activity to be sustainable with available adult resources in the future. To this end we will be involving teachers at that school in the process of elaborating our method to fit their classroom setting.

\section{Conclusion}

Our paper explored how to shape co-design / participatory design and constructionism activities as practical parts of school education through two game making case studies. First we attempted expanding previous studies for a larger group of participants with only partial success. We then evolved our initial attempt for Study 2 and developed a lightweight hybrid $\mathrm{PD} / \mathrm{CI}$ and construction activity for elementary school children which we refer to as co-construction. An adult facilitator was present in each group as a programmer and design expert who worked on an equal basis with the children. The activity appeared to maintain the positive outcomes of traditional cooperative inquiry / participatory design studies as well as some of the benefits on constructionist activities, but a larger study would be needed to quantitatively verify this claim. Additionally, co-construction proved to be a cost effective way to develop the software children designed, whilst being sufficiently lightweight to maintain and organize in a school setting which will help to enable its application across the 
curriculum in Finnish schools. Our method has been outlined in this paper and hopefully can be applied more broadly in other schools and beyond math games.

\section{Acknowledgements}

We must acknowledge our partners at Pääskyvuori School for their support in providing classrooms and students, particularly Erkki Rötkönen the principal. We would also like to thank Professor Erkki Sutinen at the University of Turku for funding and promoting this research.

\section{References}

1. Rahul Banerjee, Jason Yip, Kung Jin Lee, and Zoran Popović. 2016. Empowering Children To Rapidly Author Games and Animations Without Writing Code. In Proceedings of the The 15th International Conference on Interaction Design and Children - IDC '16.

2. Valerie Barr and Chris Stephenson. 2011. Bringing computational thinking to K-12. ACM Inroads 2, 1: 48.

3. Ahmet Baytak and Susan M. Land. 2010. A case study of educational game design by kids and for kids. Procedia Social and Behavioral Sciences 2, 2: 5242-5246.

4. Laura Benton, Asimina Vasalou, Daniel Gooch, and Rilla Khaled. 2014. Understanding and fostering children's storytelling during game narrative design. In Proceedings of the 2014 conference on Interaction design and children - IDC '14.

5. Meurig Beynon. 2012. Modelling with Experience: Construal and Construction for Software. In Ways of Thinking, Ways of Seeing, C. Bissell and C. Dillon (eds.). Springer, Berlin, Heidelberg, 197-228.

6. Meurig Beynon. 2017. Mindstorms Revisited: Making New Construals of Seymour Papert's Legacy. In Advances in Intelligent Systems and Computing. 3-19.

7. D. L. Butler and P. H. Winne. 1995. Feedback and Self-Regulated Learning: A Theoretical Synthesis. Review of educational research 65, 3: 245-281.

8. Samuel Kai Wah Chu, Rebecca B. Reynolds, Nicole J. Tavares, Michele Notari, and Celina Wing Yi Lee. 2016. 21st Century Skills Development Through Inquiry-Based Learning: From Theory to Practice. Springer.

9. Gabriella Dodero, Rosella Gennari, Alessandra Melonio, and Santina Torello. 2014. Towards tangible gamified co-design at school. In Proceedings of the first ACM SIGCHI annual symposium on Computer-human interaction in play - CHI PLAY'14.

10. Allison Druin. 1999. Cooperative inquiry: developing new technologies for children with children. In Proceedings of the SIGCHI conference on Human Factors in Computing Systems, 592-599.

11. Jeffrey Earp. 2015. Game Making for Learning: a Systematic Review of the Research Literature. In 8th International Conference of Education, Research and Innovation ICERI2015, 6426-6435.

12. Jeffrey Earp, Francesca Maria Dagnino, and Ilaria Caponetto. 2016. An Italian Pilot Experience in Game Making for Learning. In ICT in Education in Global Context, J. Zhang, J. Yang, M. Chang and T. Chang (eds.). Springer, Singapore, 171-199.
13. Jerry Alan Fails, Mona Leigh Guha, and Allison Druin. 2013. Methods and Techniques for Involving Children in the Design of New Technology for Children. Now Publishers Inc, Hanover, MA, USA.

14. Christopher Frauenberger, Judith Good, Geraldine Fitzpatrick, and Ole Sejer Iversen. 2015. In pursuit of rigour and accountability in participatory design. International journal of human-computer studies 74: 93-106.

15. Lalya Gaye and Atau Tanaka. 2011. Beyond participation: empowerment, control and ownership in youth-led collaborative design. In Proceedings of the 8th ACM conference on Creativity and cognition, 335-336.

16. R. Gennari, A. Melonio, D. Raccanello, M. Brondino, G. Dodero, M. Pasini, and S. Torello. 2017. Children's emotions and quality of products in participatory game design.

International journal of human-computer studies 101: 45-61.

17. Michail N. Giannakos, Varvara Garneli, and Konstantinos Chorianopoulos. 2015. Exploring the Importance of "Making" in an Educational Game Design. In Entertainment Computing - ICEC 2015, K. Chorianopoulos, M. Divitini, Hauge J. Baalsrud, L. Jaccheri and R. Malaka (eds.). Springer, Cham, 367-374.

18. Shuchi Grover and Roy Pea. 2013. Computational Thinking in K-12. Educational researcher 42, 1: 38-43.

19. Mona Leigh Guha, Allison Druin, and Jerry Alan Fails. 2013. Cooperative Inquiry revisited: Reflections of the past and guidelines for the future of intergenerational co-design. International Journal of Child-Computer Interaction 1, 1: 14-23.

20. Idit Harel, Seymour Papert, and Massachusetts Institute of Technology. Epistemology \& Learning Research Group. 1991. Constructionism: research reports and essays, 1985-1990. Ablex Publishing Corporation.

21. Antony Harfield, Rene Alimisi, Peter Tomcsányi, Nick Pope, and Meurig Beynon. 2016. Constructionism as making construals: first steps with JS-Eden in the classroom. In Proceedings of Constructionism 2016, 42-52.

22. Bassam Hasan. 2003. The influence of specific computer experiences on computer self-efficacy beliefs. Computers in human behavior 19, 4: 443-450.

23. John Hattie and Helen Timperley. 2007. The Power of Feedback. Review of educational research 77, 1: 81-112.

24. Caroline M. Heary and Eilis Hennessy. 2002. The use of focus group interviews in pediatric health care research. Journal of pediatric psychology 27, 1: 47-57.

25. Danah Henriksen. 2017. Creating STEAM with Design Thinking: Beyond STEM and Arts Integration. STEAM 3, 1: $1-11$.

26. Alan R. Hevner. 2007. The Three Cycle View of Design Science Research. Scandinavian Journal of Information Systems 19, 2: 87.

27. Ole Sejer Iversen and Christian Dindler. 2014. Sustaining participatory design initiatives. CoDesign 10, 3-4: 153-170.

28. Ole Sejer Iversen, Rachel Charlotte Smith, and Christian Dindler. 2017. Child as Protagonist: Expanding the Role of Children in Participatory Design. In Proceedings of the 2017 Conference on Interaction Design and Children, 27-37.

29. Yasmin B. Kafai. 2006. Playing and Making Games for Learning. Games and Culture 1, 1: 36-40.

30. Yasmin B. Kafai and Quinn Burke. 2015. Constructionist Gaming: Understanding the Benefits of Making Games for Learning. Educational psychologist 50, 4: 313-334.

31. Fengfeng Ke. 2014. An implementation of design-based 
learning through creating educational computer games: A case study on mathematics learning during design and computing. Computers \& education 73: 26-39.

32. Rilla Khaled and Asimina Vasalou. 2014. Bridging serious games and participatory design. International Journal of Child-Computer Interaction 2, 2: 93-100.

33. Kristian Kiili. 2005. Digital game-based learning: Towards an experiential gaming model. The Internet and Higher Education 8, 1: 13-24.

34. Kristian Kiili, Carita Kiili, Michela Ott, and Teemu Jonkkari. 2012. Towards creative pedagogy: Empowering students to develop games. In European Conference on Games-based Learning.

35. David A. Kolb. 2014. Experiential Learning: Experience as the Source of Learning and Development. FT Press.

36. Leena Kuure, Eija Halkola, Netta Iivari, Marianne Kinnula, and Tonja Molin-Juustila. 2010. Children imitate! In Proceedings of the 11th Biennial Participatory Design Conference on - PDC '10.

37. Samuli Laato, Teemu H. Laine, Jungryul Seo, Wooryeon Ko, and Erkki Sutinen. 2017. Designing a Game for Learning Math by Composing: A Finnish Primary School Case. In 2017 IEEE 17th International Conference on Advanced Learning Technologies (ICALT). https://doi.org/10.1109/icalt.2017.45

38. Alessandra Melonio. 2017. Is Participatory Game Design Effective Over Time? Let's Assess Its Products. In Lecture Notes in Information Systems and Organisation. 81-93.

39. Marije Nouwen, Selina Schepers, Karen Mouws, Karin Slegers, Niek Kosten, and Pieter Duysburgh. 2016. Designing an educational music game: What if children were calling the tune? International Journal of Child-Computer Interaction 9-10: 20-32.

40. Seymour Papert. 1982. Mindstorms.

41. Arttu Perttula, Pauliina Tuomi, Kristian Kiili, and Antero Lindstedt. 2016. Promoting students' fractional thinking by challenging them to design game-based number line tasks for others. In Proceedings of the 20th International Academic Mindtrek Conference on - AcademicMindtrek'16.

42. Jean Piaget. 1970. Piaget's Theory.

43. David Preston. 2005. PAIR programming as a model of collaborative learning: a review of the research. Journal of Computing Sciences in Colleges 20, 4: 39-45.

44. Meihua Qian and Karen R. Clark. 2016. Game-based Learning and 21st century skills: A review of recent research. Computers in human behavior 63: 50-58.

45. Janet C. Read, Daniel Fitton, and Matthew Horton. 2014. Giving ideas an equal chance: inclusion and representation in participatory design with children. In Proceedings of the 2014 conference on Interaction design and children, 105-114.

46. Janet Read, Peggy Gregory, Stuart Macfarlane, Barbara Mcmanus, Peter Gray, and Raj Patel. 2002. An investigation of participatory design with children-informant, balanced and facilitated design. In Interaction design and Children, 53-64.

47. Alexander Repenning. 2013. Making Programming Accessible and Exciting. Computer 46, 6: 78-81.

48. A. Repenning and T. Sumner. 1995. Agentsheets: a medium for creating domain-oriented visual languages. Computer 28, 3: $17-25$.

49. Mitchel Resnick, John Maloney, Andrés Monroy-Hernández, Natalie Rusk, Evelyn Eastmond, Karen Brennan, Amon Millner, Eric Rosenbaum, Jay Silver, Brian Silverman, and Yasmin Kafai. 2009. Scratch: programming for all. Communications of the ACM 52, 11: 60-67.
50. Elizabeth B-N Sanders and Pieter Jan Stappers. Co-creation and the new landscapes of design. Design: Critical and Primary Sources.

51. Bernd Carsten Stahl. 2014. Participatory design as ethical practice - concepts, reality and conditions. Journal of Information, Communication and Ethics in Society 12, 1: 10-13.

52. Maarten Van Mechelen, Mathieu Gielen, Vero vanden Abeele, Ann Laenen, and Bieke Zaman. 2014. Exploring challenging group dynamics in participatory design with children. In Proceedings of the 2014 conference on Interaction design and children - IDC '14.

53. Maarten Van Mechelen, Gavin Sim, Bieke Zaman, Peggy Gregory, Karin Slegers, and Matthew Horton. 2014. Applying the CHECk tool to participatory design sessions with children. In Proceedings of the 2014 conference on Interaction design and children - IDC '14.

54. Greg Walsh, Alison Druin, Mona Leigh Guha, Elizabeth Foss, Evan Golub, Leshell Hatley, Elizabeth Bonsignore, and Sonia Franckel. 2010. Layered elaboration: a new technique for co-design with children. In Proceedings of the SIGCHI Conference on Human Factors in Computing Systems, 1237-1240.

55. Greg Walsh, Elizabeth Foss, Jason Yip, and Allison Druin. 2013. FACIT PD. In Proceedings of the SIGCHI Conference on Human Factors in Computing Systems - CHI '13.

56. David Weintrop, Nathan Holbert, Michael S. Horn, and Uri Wilensky. 2016. Computational Thinking in Constructionist Video Games. International Journal of Game-Based Learning 6, 1: 1-17.

57. Jeannette M. Wing. 2006. Computational thinking. Communications of the ACM 49, 3: 33.

58. Jason C. Yip, Kiley Sobel, Caroline Pitt, Kung Jin Lee, Sijin Chen, Kari Nasu, and Laura R. Pina. 2017. Examining Adult-Child Interactions in Intergenerational Participatory Design. In Proceedings of the 2017 CHI Conference on Human Factors in Computing Systems - CHI '17.

59. 2002. Partnership for 21 st Century Learning. P21. Retrieved January 11, 2018 from http://www.p21.org

60. Finnish Curriculum 2016. Retrieved January 11, 2018 from http://www.oph.fi/ops2016/perusteet

61. Making Construals Environment. Construit. Retrieved January 10, 2018 from http://construit.co.uk/mce

62. Math Snake. Construit. Retrieved January 10, 2018 from http://construit.co.uk/mce/?load $=334 \& v i d=5395 \& \mathrm{r}=$

63. Goldfist Games. Construit. Retrieved January 10, 2018 from http://construit.co.uk $/ \mathrm{mce} /$ ?load $=333 \&$ vid $=5444 \& \mathrm{r}=$ 